\title{
Furfural Synthesis from Mikania micrantha using Tamarind Extract as Catalyst
}

\author{
Taslim*, Sundari Pratiwi, Apri Wardiana Sinaga, and Iriany \\ Department of Chemical Engineering, Faculty of Engineering, Universitas Sumatera Utara, Medan 20155, Indonesia.
}

ORCID: 0000-0003-0482-320X

\begin{abstract}
:
The use of inorganic acid catalyst in furfural synthesis from biomass cause equipment corrosion and waste disposal since waste of the inorganic acid catalyst can damage environment. To overcome these issues, organic acid catalyst could be considered as an alternative. The purpose of this work was to examine the utilization of organic acid derived from tamarind as catalyst and compare it with sulfuric acid catalyst. Mikania micrantha (MC) was used as a feedstock. As much as $50 \mathrm{~g}$ dry MC was pulverized to 70 mesh and mixed with $50 \mathrm{~g}$ sodium chloride. This mixture was added into tamarind extract at ratio of $1: 6(\mathrm{w} / \mathrm{v})$ in a three neck round bottom flask equipped with condenser, stirrer, and thermometer. The reaction was performed at $100-120^{\circ} \mathrm{C}$ and for $0-330 \mathrm{~min}$. Crude furfural was extracted by adding $50 \mathrm{ml}$ chloroform. After extraction two layer were occurred, the bottom layer was furfural and chloroform, and the top layer was rich in water. Furfural and chloroform was separated by distillation process at $60-70^{\circ} \mathrm{C}$. The furfural obtained was characterized by aniline acetate reagent, density test, infrared spectrophotometer, and GC-MS. The results confirmed that organic acids from tamarind extraction can be used as a catalyst in furfural formation.
\end{abstract}

Keywords: Mikania micrantha, tamarind extract, hydrolysis, pentosan, furfural

\section{INTRODUCTION}

Lignocellulosic biomass is the most plentiful renewable resource and promising raw material for producing biochemical and biofuel-based commodities [1]. It consists of $42-54 \%$ cellulose, $22-28 \%$ lignin, and $23-36 \%$ hemicellulose. The most common type of hemicelluloses is xylan, a polymer of pentose sugar (xylose) which is generally found in dicotyledonous plants [2,3]. One of the dicotyledonous biomass is Mikania micrantha (MC).

$\mathrm{MC}$ is known as one of the most rampant weed species in the world because of its fast-growing characteristics, surrounding other plants which can cause the plants to lack sunlight and die [4]. The main chemical composition of MC is pentosan, holocellulose, and lignin with each composition of 49.54$56.04 \%, 14.05 \pm 0.18 \%$, and $23.54 \pm 0,89 \%$ [3,5]. Biomass with high pentosan content is suitable as a precursor of furfural. Furfural is an intermediate compound for chemical and biofuel-based industry. It can be used in the production of antacids, paints, and additives in fuels [6].

Furfural is industrially produced through hydrolysis and dehydration by strong thermal acid catalyst. The strong acid catalyst used is usually inorganic acid which can cause corrosion to the equipment and release residue which can contaminate the environment. To overcome these issues and have a more environmentally friendly process, an organic acid catalyst can be considered as an alternative [5]. The use of organic acid from bilimbi acid as catalyst in the furfural formation from MC can produce furfural yield of 7.2\% [5]. The mechanism of furfural formation is shown in Fig 1.

The utilization of organic acids from tamarind has never been reported before. In fact, tamarind extract contains high organic acids such as tartaric acid, oxalic acid, citric acid, and maleic acid [8]. Therefore, this work was emphasized in the use of tamarind extract as a catalyst in furfural production from MC, and compare it with sulfuric acid catalyst.

\section{MATERIALS AND METHODS \\ II.I. MATERIALS}

MC was obtained from Kampung Susuk Medan. All chemicals used in this work such as sodium chloride $(\mathrm{NaCl})$, sulfuric acid $\left(\mathrm{H}_{2} \mathrm{SO}_{4}\right)$, aniline $\left(\mathrm{C}_{6} \mathrm{H}_{5} \mathrm{NH}_{2}\right)$, acetic acid $\left(\mathrm{CH}_{3} \mathrm{COOH}\right)$, and chloroform $\left(\mathrm{CHCl}_{3}\right)$ were supplied by $\mathrm{RJ}$ Medan.

\section{II.II. PREPARATION OF MC POWDER}

Before processing, stems and leaves of MC were separated, then washed with water to remove dissolved impurities. Then each part of stems and leaves were cut to a size of $\pm 1 \mathrm{~cm}$. After that, each stem and leaves were dried in an oven at $100^{\circ} \mathrm{C}$ for 4 hours, then pulverized using ball mill for 5 hours. Then the product was sieved to size of 70 mesh in order to obtain uniform powder size [5]. The powder with a composition mixture of stems and leaves 1:1 was used as raw material in furfural synthesis. It was stored in a closed plastic vessel at room temperature.

\section{II.III. TAMARIND EXTRACTION}

Extraction of tamarind followed the procedure carried out by Taslim et al. [5]. Tamarind fruit that has been freed from the shell and seeds and were put into a perforated container and then washed to remove dissolved contaminants using water streams. Then, the cleaned flesh of tamarind and water in a ratio of 1:2(w/v) were blended using a blender to produce 
tamarind juice. Afterward, the juice was filtered with Whatman filter paper no. 41. The normality, acid number, and $\mathrm{pH}$ of tamarind filtrate were analyzed and stored in a refrigerator at $0^{\circ} \mathrm{C}$.

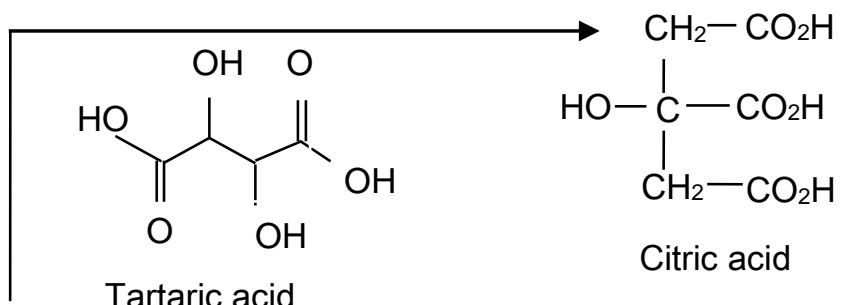<smiles>O=C(O)C(=O)O</smiles><smiles>CC(C)(C)CC(=O)O</smiles>

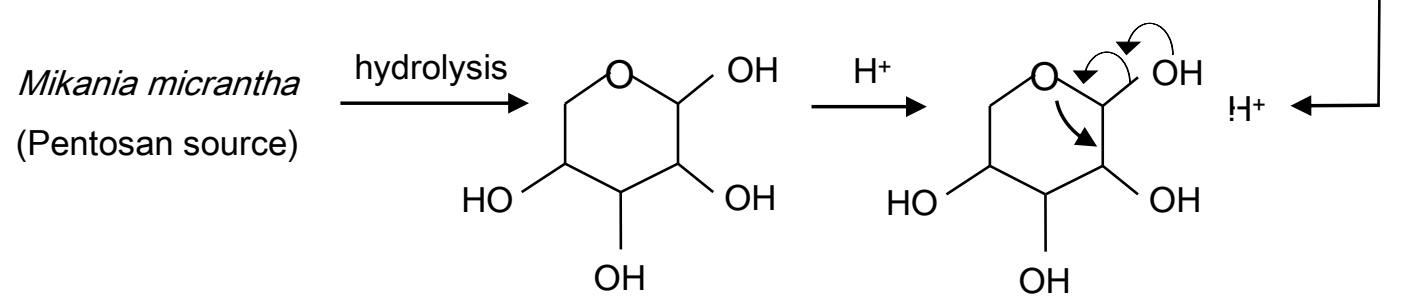

Pentose<smiles>O=CC(O)=C(O)C([18OH])CO</smiles>

Xylulose

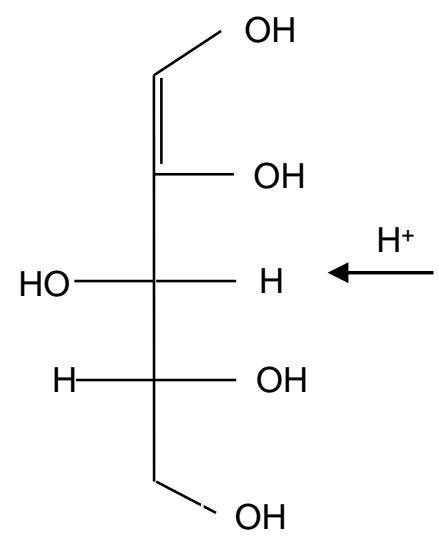

1,2-Enediol<smiles>CC(=O)C(O)C(O)C(O)CO</smiles>

Xylose

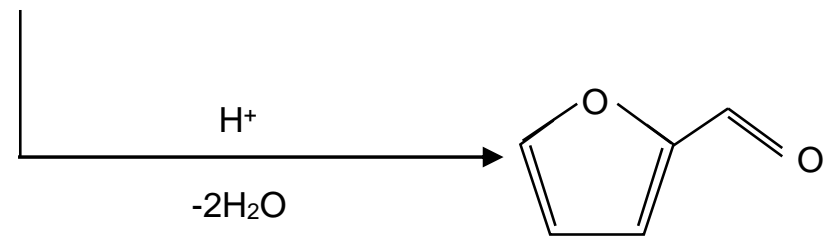

Furfural

Fig 1. The mechanism of furfural production [5,7] 


\section{II.IV. FURFURAL SYNTHESIS}

As much as $50 \mathrm{~g}$ MC powder was mixed with $50 \mathrm{~g} \mathrm{NaCl}$. The mixture was added into tamarind extract at ratio of 1:6 (w/v), in measuring cup of $1 \mathrm{~L}$. The total volume of the mixture was set to $750 \mathrm{~mL}$ by adding distilled water [5]. The mixture was then fed into in a three neck round bottom flask equipped with condenser, stirrer, and thermometer. The reaction was performed at $100-120^{\circ} \mathrm{C}$ and for $0-330 \mathrm{~min}$. Crude furfural obtained was extracted by adding $50 \mathrm{ml}$ chloroform. After extraction two layer were occurred, the bottom layer was furfural and chloroform, and the top layer was rich in water. Furfural and chloroform was separated by distillation process at $60-70^{\circ} \mathrm{C}$. The upper layer was rich in water and the lower layer was the mixture of furfural and chloroform. The lower layer was further distilled to purify furfural by evaporating chloroform compound. The volume of purified furfural obtained was collected and recorded.

\section{V. FURFURAL IDENTIFICATION}

The furfural obtained was identified by color test of aniline acetate reagent (1:1), density test, FTIR (Fourier Transform Infra Red), and GC-MS (Gas Chromatography - Mass Spectrometer).

\section{RESULTS AND DISCUSSION}

\section{III.I. PRELIMINARY ANALYSIS OF MC}

Based on preliminary analysis in this study, the water content of mixture of leaves and stems of MC was $84.54 \%$. The pentosan level of MC was $55.02 \%$. This value was very similar to that reported in the literature at $56.04 \%$ [3].

\section{III.II. EFFECT OF REACTION TIME ON FURFURAL YIELD}

The influence of reaction time on furfural yield at various temperatures revealed that yield increased significantly during initial phase and decreased after longer reaction time, as in Fig 2. Results indicated that, furfural was formed at reaction time of $30 \mathrm{~min}$ for reaction temperature of $120^{\circ} \mathrm{C}$ when using tamarind extract as catalyst, while for the reaction temperature of $100^{\circ} \mathrm{C}$ and $110^{\circ} \mathrm{C}$, furfural was formed at reaction time of $60 \mathrm{~min}$ and $90 \mathrm{~min}$. In all reaction temperature tested, furfural yield was initially increasing and peaked at reaction time of $270 \mathrm{~min}$. At minute 300 till minute 330, furfural yield gradually decreased. For $20 \%$ sulfuric acid catalyst furfural was formed within $30 \mathrm{~min}$ and subsequently increased until 180 minutes at reaction temperature of $120^{\circ} \mathrm{C}$.

The yield increase implies that xylose was highly accessible in the biomass. As reaction progresses, acetyl groups in hemicellulose decompose into acetic acid. However, longer reaction time also triggers side reaction in which furfural is degraded into small molecule and furfural resinification. In addition, furfural may also experience a condensation reaction with xylose to produce insoluble polymers such as humin [9]. As the result, furfural yield decreases when reaction time is too long.

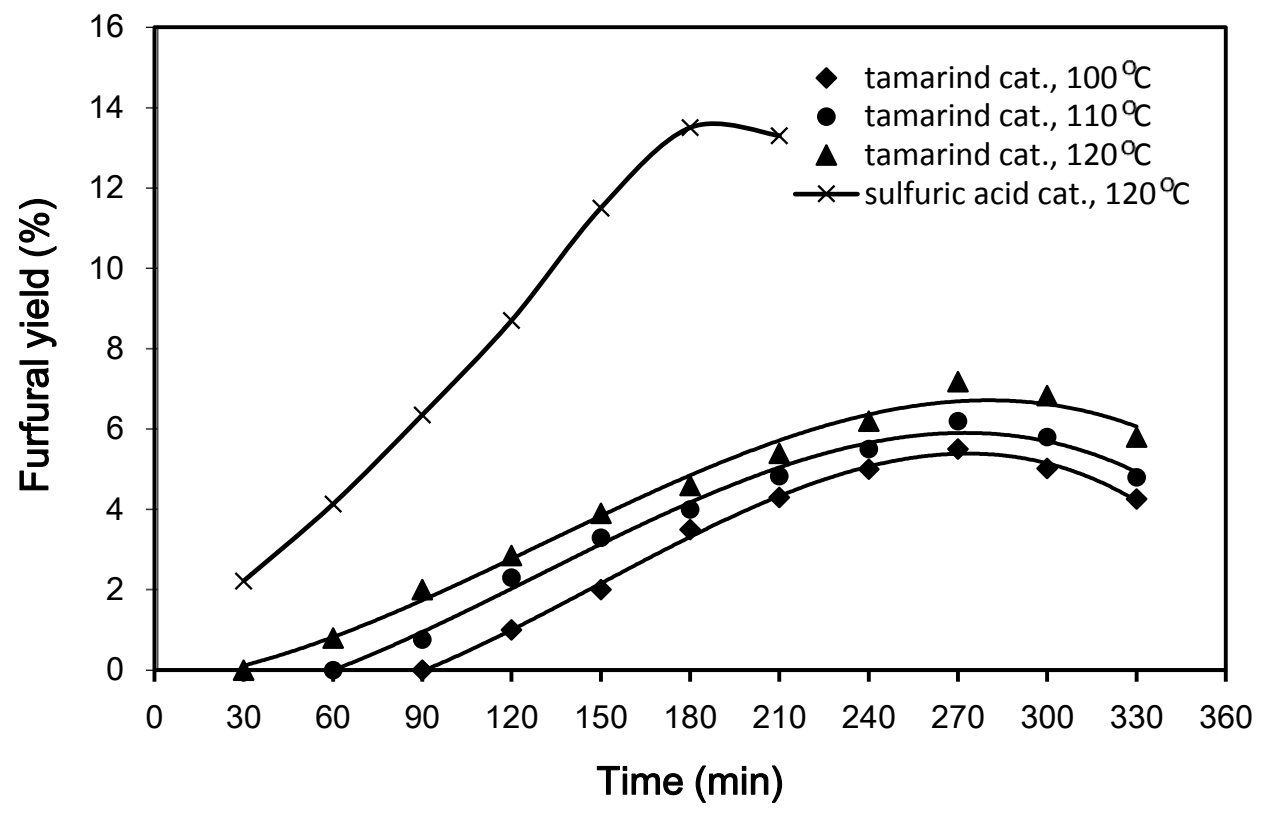

Fig 2. The effect of reaction time on furfural yield at various temperatures 
International Journal of Engineering Research and Technology. ISSN 0974-3154, Volume 13, Number 1 (2020), pp. 151-157

(C) International Research Publication House. https://dx.doi.org/10.37624/IJERT/13.1.2020.151-157

Table 1. Catalysts comparison in furfural synthesis

\begin{tabular}{cccccc}
\hline Catalyst & $\begin{array}{c}\text { Volume } \\
(\mathrm{ml})\end{array}$ & $\mathrm{pH}$ & $\begin{array}{c}\text { Acid number } \\
(\mathrm{mg} / \mathrm{g})\end{array}$ & $\begin{array}{c}\text { Highest yield } \\
(\%)\end{array}$ & Condition \\
\hline Tamarind extract & 600 & 2.6 & 14.01 & 7.18 & $\left(100^{\circ} \mathrm{C}, 270 \mathrm{~min}\right)$ \\
$20 \%$ Sulfuric acid & 600 & 0.2 & 200.4 & 13.5 & $\left(120^{\circ} \mathrm{C}, 180 \mathrm{~min}\right)$ \\
\hline
\end{tabular}

Based on Fig 2, it can be deduced that the highest furfural yield for tamarind extract catalyst at 330 minutes and temperature of $120^{\circ} \mathrm{C}$ was $7.18 \%$, while for sulfuric acid catalyst a yield of $13.5 \%$ has been reached in 180 minutes at the same temperature. This is because the rate of the hydrolysis reaction was affected by the presence of $\mathrm{H}^{+}$ions in solution, so the larger content of $\mathrm{H}^{+}$ion, the faster the reaction rate will be achieved, and produced more hydrolysis products [10]. The content of $\mathrm{H}^{+}$ion in sulfuric acid catalyst indicated by acid number which value was 14.3 times greater than tamarind extract catalyst. The $\mathrm{pH}$ of $20 \%$ sulfuric acid catalyst was 0.2 while the tamarind extract catalyst was 2.6 . Table 1 presents a comparison of the catalyst used in the furfural production

\section{III.III. FURFURAL IDENTIFICATION}

\section{III.III.1. Aniline acetate reagent test}

Aniline and acetate in a ratio of $1: 1(\mathrm{v} / \mathrm{v})$ reagent test is a qualitative analysis that identify the presence of furfural with the change in sample color to brick red when added with aniline acetate reagent [5]. From the results obtained at $120^{\circ} \mathrm{C}$, for tamarind extract catalyst and sulfuric acid catalyst, the color of sample changed from yellowish to brick red. The brick red color shown by sulfuric acid catalyst was darker than tamarind extract catalyst. This indicates that furfural contained by using sulfuric acid was greater than by using tamarind extract catalyst.

\section{III.III.II. FTIR analysis}

The results of the FTIR analysis in Fig 3 show the functional groups found in furfural. Based on Fig 3, the higher absorption occurred at wave numbers $1675.98 \mathrm{~cm}^{-1}$ and $1671.21 \mathrm{~cm}^{-1}$ respectively for tamarind extract catalyst and sulfuric acid catalyst. Absorption in that area indicates the presence of $\mathrm{C}=\mathrm{O}$ carbonyl functional groups. $\mathrm{C}-\mathrm{H}$ aldehyde bonds absorb in the region of $2853.97 \mathrm{~cm}^{-1}$ on the tamarind extract catalyst and $2849.45-2810.62 \mathrm{~cm}^{-1}$ on the sulfuric acid catalyst. As for aromatic $\mathrm{C}-\mathrm{H}$ bond, absorbed in the area of $3019.63 \mathrm{~cm}^{-1}$ for tamarind extract catalyst and 3021.24$3133.92 \mathrm{~cm}^{-1}$ for sulfuric acid catalyst. C-O-C bond absorb in the region of $1019.07-1277.01 \mathrm{~cm}^{-1}$ for sulfuric acid catalyst. For sulfuric acid catalyst, the presence of aromatic $\mathrm{C}=\mathrm{C}$ was shown at vibrations of $1567.77 \mathrm{~cm}^{-1}$. Based on furfural vibration values from the litarure, it can be confirmed that the compound produced in this study was furfural [11].

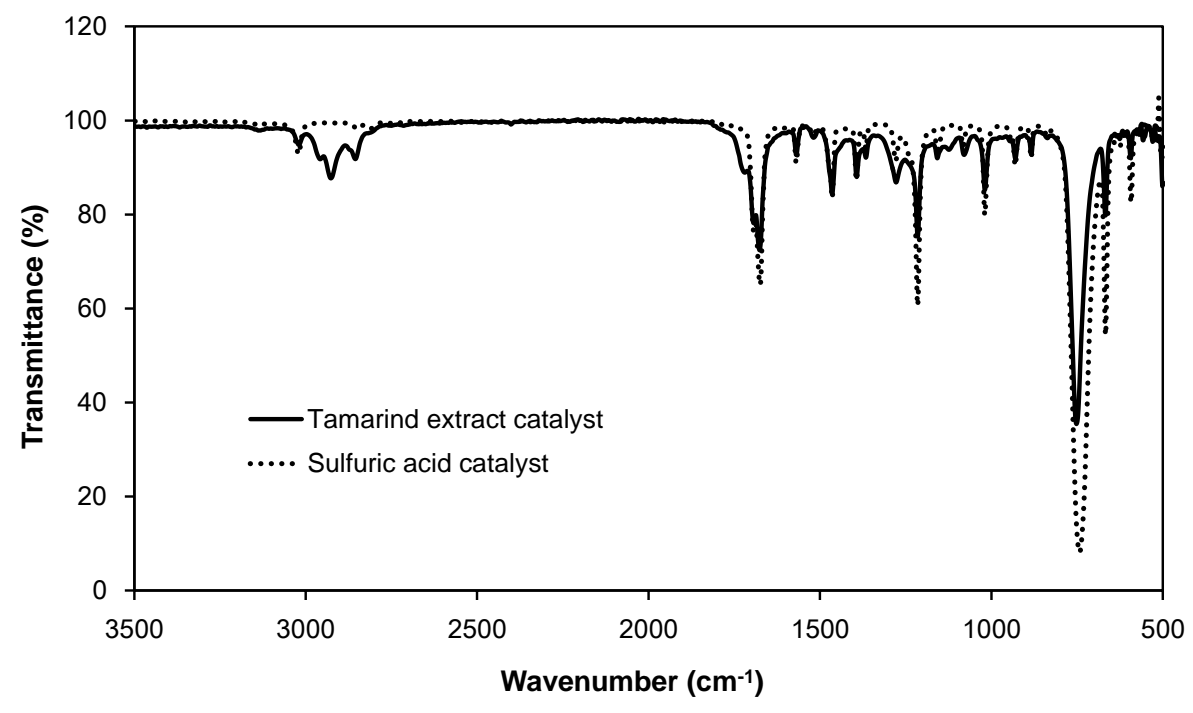

Fig 3. FTIR analysis using tamarind extract and sulfuric acid catalyst 


\section{III.III.III. Furfural density test}

The density analysis results obtained in this work at $120^{\circ} \mathrm{C}$ and $270 \mathrm{~min}$ for tamarind extract catalyst was $1.1567 \mathrm{~g} / \mathrm{cm}^{3}$ and for sulfuric acid catalyst was $1.1603 \mathrm{~g} / \mathrm{cm}^{3}$ close to the standard furfural density value based on the literature. In the literature, the value of furfural density at $25^{\circ} \mathrm{C}$ was $1.16 \mathrm{~g} / \mathrm{cm}^{3}$ $[11,12]$.

\section{III.III.IV. GC-MS analysis}

The results of furfural analysis with GC-MS can be seen in Fig 4 and 5. Fig 4 shows a quantity result of furfural compound from hydrolysis process using GC. This is shown at peak 4 (Fig 4a) with a retention time of 7.604 min and area of $62.99 \%$ for tamarind extract catalyst, while for a $20 \%$ sulfuric acid catalyst, it is shown at peak 1 with a retention time of $8.975 \mathrm{~min}$ and area of $100 \%$ (Fig 4b). Mass spectroscopy is usually used to investigate the molecular weight of a chemical compounds and the molecular structure based on the result of fragmentation patterns. The results of mass spectroscopy from GC-MS are shown in Fig 5.

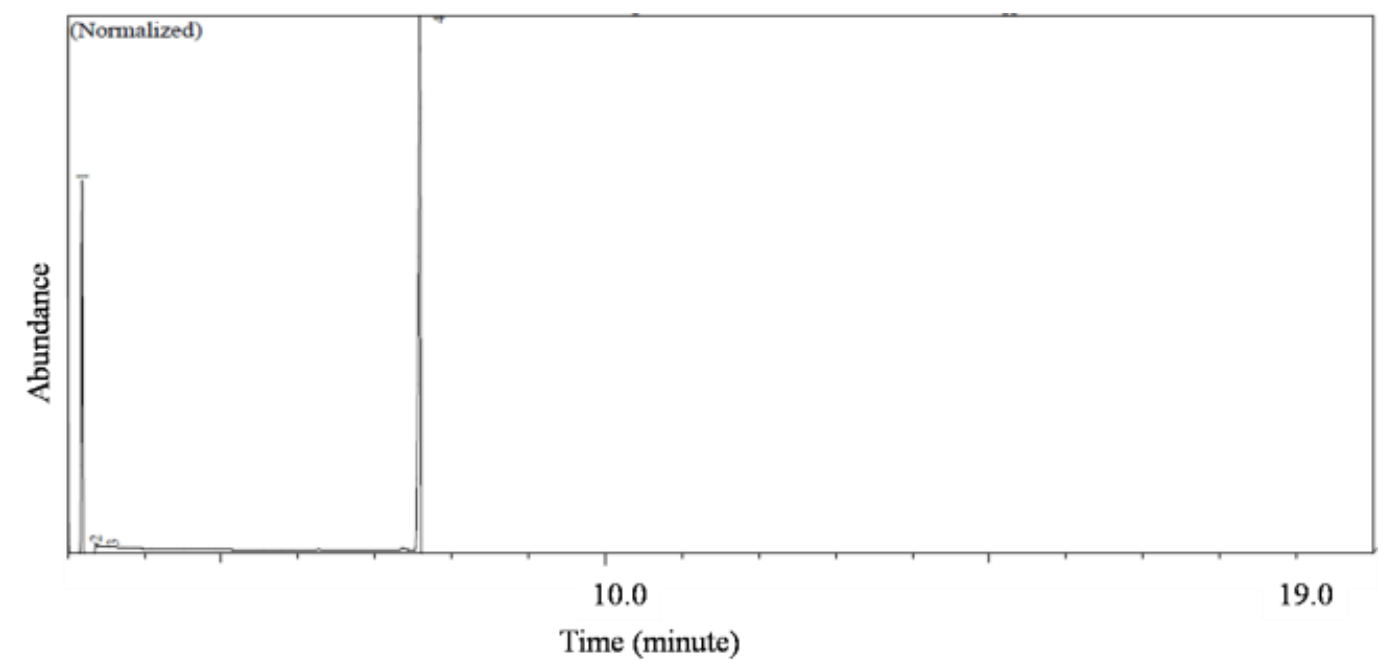

(a)

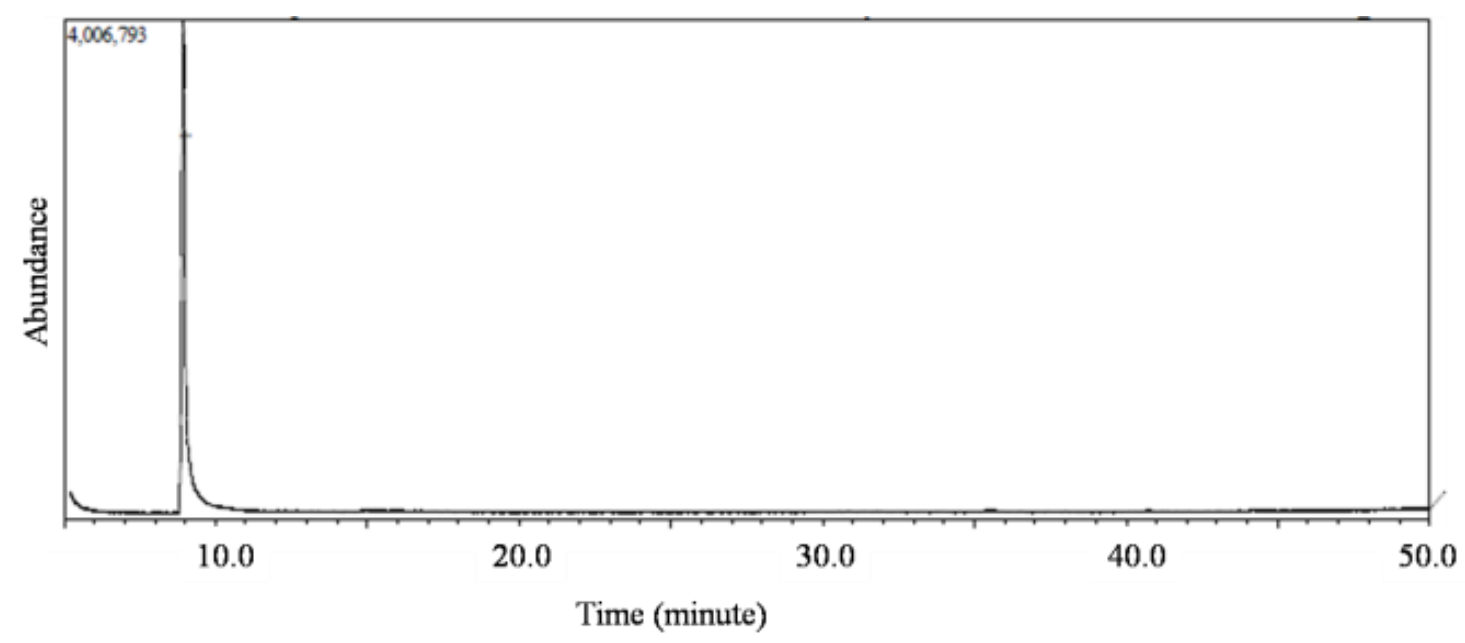

(b)

Fig 4. Gas Chromatography Analysis: (a). tamarind extract catalyst, (b) 20\% sulfuric acid catalyst 
Fragmentation patterns were the result of the shooting of highenergy electrons. During the energy range, the furfural cation $\left(\mathrm{C}_{5} \mathrm{H}_{4} \mathrm{O}_{2}{ }^{+}, \mathrm{m} / \mathrm{z}=96\right)$ decays into four dissociation channels with the formation of a branch ion for both catalysts as follows: $\mathrm{C}_{4} \mathrm{H}_{3} \mathrm{O}^{+}(\mathrm{m} / \mathrm{z}=67), \mathrm{C}_{3} \mathrm{H}_{3}{ }^{+}(\mathrm{m} / \mathrm{z}=39), \mathrm{C}_{2} \mathrm{H}_{2} \mathrm{O}^{+}(\mathrm{m} / \mathrm{z}=$ $42)$, and $\mathrm{C}_{2} \mathrm{H}_{2}{ }^{+}(\mathrm{m} / \mathrm{z}=26)$. With a base peak at $\mathrm{m} / \mathrm{z} 96$ which is the value of the mass/charge ratio for furfural. This is depicted in Fig $5 \mathrm{a}$ and $5 \mathrm{~b}$.

The dissociation mechanism started from the loss of $\mathrm{CO}$ groups and $\mathrm{H}$ ions from furfural cations to produce $\mathrm{m} / \mathrm{z}=67$
$\left(\mathrm{C}_{4} \mathrm{H}_{3} \mathrm{O}^{+}\right)$fragment ions, within the same energy range, there was also a slight increase in $\mathrm{m} / \mathrm{z}=39\left(\mathrm{C}_{3} \mathrm{H}_{3}{ }^{+}\right)$ions. Then the fragment ion $\mathrm{m} / \mathrm{z}=42\left(\mathrm{C}_{2} \mathrm{H}_{2} \mathrm{O}^{+}\right)$appearred as a result of further description of the cation $\mathrm{m} / \mathrm{z}=67$. Then, losing $\mathrm{C}_{3} \mathrm{H}_{3}{ }^{+}$ as the dissociation channel of the fragment $\mathrm{m} / \mathrm{z}=67\left(\mathrm{C}_{4} \mathrm{H}_{3} \mathrm{O}^{+}\right)$ will form the fragment ion $\mathrm{m} / \mathrm{z}=26\left(\mathrm{C}_{2} \mathrm{H}_{2}{ }^{+}\right)$[14]. The fragmentation patterns and names of the elements produced by the roselle extract catalyst and the $20 \%$ sulfuric acid catalyst are shown in Table 2.

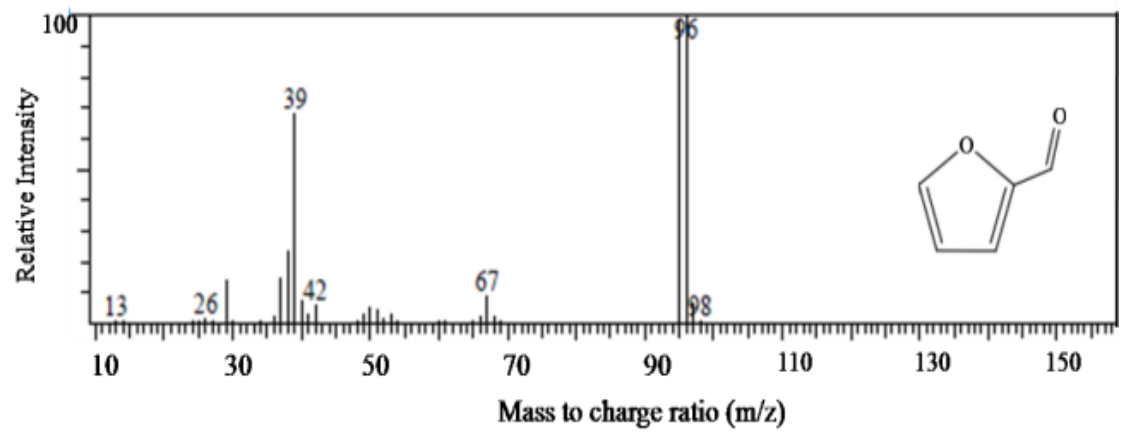

(a)

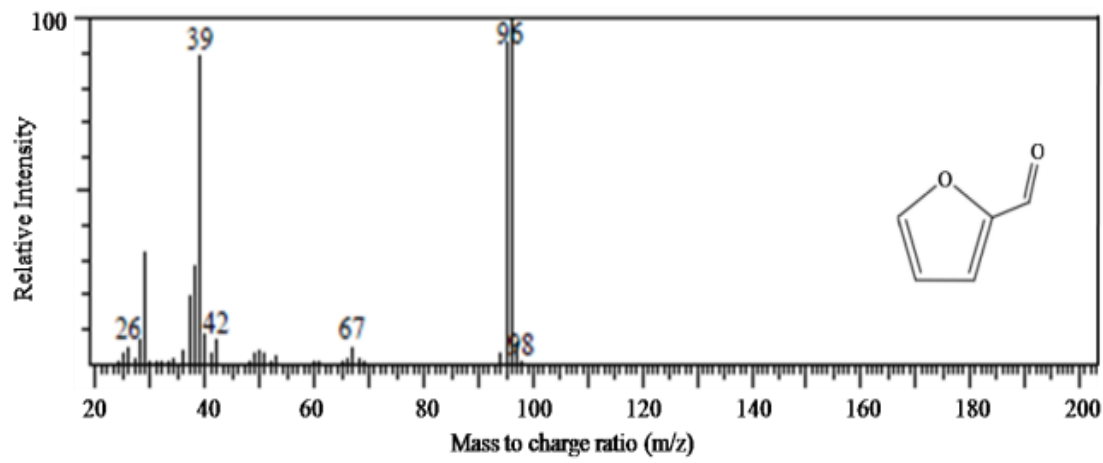

(b)

Fig 5. Mass spectroscopy analysis from GC-MS : (a) tamarind extract catalyst, $20 \%$ sulfuric acid

The obtained base peak value approaches the standard furfural molecular formula which is 96.0841 [12,14] with a fragmentation value $(\mathrm{m} / \mathrm{z})$ that corresponds to the standard furfural $\mathrm{m} / \mathrm{z}$ value.

Table 2. Fragmentation patterns for tamarind extract catalyst and $20 \%$ sulfuric acid catalyst

\begin{tabular}{lll}
\hline Compound & $\mathrm{m} / \mathrm{z}$ & Elements composition \\
\hline & 96 & $\mathrm{C}_{5} \mathrm{H}_{4} \mathrm{O}_{2}{ }^{+}$(Furfural) \\
& 67 & $\mathrm{C}_{4} \mathrm{H}_{3} \mathrm{O}$ (2-Furyl) \\
Furfural & 42 & $\left(\mathrm{C}_{2} \mathrm{H}_{2} \mathrm{O}\right)^{+}$(Ketene) \\
& 39 & $\mathrm{C}_{3} \mathrm{H}_{3}{ }^{+}$(Cyclopropenyl) \\
& 26 & $\mathrm{C}_{2} \mathrm{H}_{2}{ }^{+}$(Acetylen) \\
\hline
\end{tabular}

\section{CONCLUSION}

Based on the results of the analysis, organic acid from tamarind can be used as a catalyst in furfural synthesis from $\mathrm{MC}$ with the highest yield of $7.18 \%$ at $120{ }^{\circ} \mathrm{C}$ and $270 \mathrm{~min}$. Analysis using FTIR identified aldehyde group that represented the presence of furfural in wavenumber 2853.97 and $2849.45-2810.62 \mathrm{~cm}^{-1}$ respectively for tamarind extract catalyst and sulfuric acid catalyst. Analysis using GCMS showed furfural compounds at a retention time of 7.604 and $8.975 \mathrm{~min}$ for the tamarind extract catalyst and sulfuric acid catalyst, respectively, with a mass/charge $(\mathrm{m} / \mathrm{z})$ value of 96 which corresponds to the standard furfural $\mathrm{m} / \mathrm{z}$ value. 


\section{REFERENCES}

[1] L Zhang, and H. Yu, Conversion of xylan and xylose into furfural in biorenewable deep eutetic solvent with trivalent metal chloride added, Bioresource, 8(4), 2013, 6014-6025.

[2] L. Senila, M. Miclean, M. Senila, M. Roman, and C. Roman, New analysis method of furfural bbtained from wood applying an autohydrolysis pretreatment, Romanian Biotechnological Letters, 18(1), 2013, 79477955.

[3] C.H. Ko, T. L. Shih, B.T. Jhan, F.C. Chang, Y.N. Wang, and Y.C. Wang, Production of xylooligosaccharides from forest waste by membrane separation and Paenibacillus xylanase hydrolysis. BioResources, 8(1), 2013, 612-627.

[4] A. Matawali, L.P. Chin, H.S. Eng, and J.A. Gansau, Antibacterial and Phytochemical Investigation of Mikania micrantha H.B.K. (Asteraceae) from Sabah, Malaysia Transactions on Science and Technology, 3(1-2), 2016, 244-250.

[5] Taslim, M. Mirnandaulia, Iriany, and R. Tambun, Furfural production from mile-a-minute weed (Mikania micrantha) using rrganic acid from bilimbi (Averrhoa bilimbi), Asian Journal of Chemistry, 30(5), 2018, 1007-1011.

[6] J. Eoguche, A.O. Ameh, Y. Tanimu, and S.A. Egu, Determination and optimization of effect of process parameters on furfural yield from microalgae, $F U W$ Trends in Science and Technology Journal, 2(2), 2017, 782-787.

[7] K. Yan, G. Wu, T. Lafleur, and C. Jarvis, Production, properties and catalytic hydrogenation of furfural to fuel additives and value-added chemicals, Renewable and Sustainable Energy Reviews, 38, 2014, 663-676.

[8] F.R. Hamacek, P.R.G. Santos L.D.M. Cardoso, and H.M Pinheiro-Sant'ana, Nutritional composition of tamarind (Tamarindus indica L.) from the cerrado of minas gerais, Brazil. Fruits, 68, 2013, 381-395.

[9] L. Liu, H. M. Chang, H. Jameel, and S. Park, Furfural production from biomass pretreatment hydrolysate using vapor-releasing reactor system, Bioresource Technology, 252, 2018, 165-171.

[10] X. Li, Q. Liu, L. Peng, R. Liu, Y.Y. Li, dan X. Lan, Furfural Produced from Bamboo by A 2-step Method at Atmospheric Pressure, Journal of Chemichal and Pharmacentical Research, 6(5), 2014, 836-842.

[11] National Institute of Advanced Industrial Science and Technology (AIST), Furfural. https://www.aist.go.jp/index_en. html, 1999.

[12] G. Machado, S. Leon, F. Santos, R. Lourega, J. Dullius, M. E. Mollman, and P. Eicher, Literature review on furfural production from lignocellulosic biomass, Natural Resources, 7, 2016, 115-129.

[13] M. Winfough, K. Voronova, G. Muller, G. Laguisma, B. Sztaray, A. Bodi, and G. Meloni, Furfural: the unimolecular dissociative photoionization mechanism of the simplest furanic aldehyde, The Journal of
Physical Chemistry, 12, 2017, 3401-3410.

[14] National Institute Standards of Technology (NIST), Furfural.https://webbook. nist.gov/cgi/cbook.cgi?ID=98-01-1, 2019 